\title{
Thermal Inequity in Richmond, VA: The Effect of an Unjust Evolution of the Urban Landscape on Urban Heat Islands
}

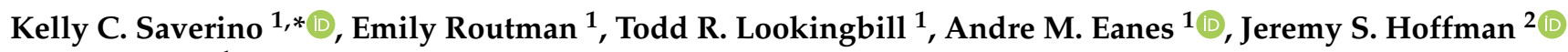 \\ and Rong Bao ${ }^{1}$ \\ 1 Department of Geography and the Environment, University of Richmond, Richmond, VA 23173, USA; \\ em.routman@gmail.com (E.R.); tlooking@richmond.edu (T.R.L.); andre.eanes@richmond.edu (A.M.E.); \\ rong.bao@richmond.edu (R.B.) \\ 2 Science Museum of Virginia, Richmond, VA 23220, USA; jhoffman@smv.org \\ * Correspondence: kelly.saverino@richmond.edu; Tel.: +1-732-540-0422
}

Citation: Saverino, K.C.; Routman, E.; Lookingbill, T.R.; Eanes, A.M. Hoffman, J.S.; Bao, R. Thermal Inequity in Richmond, VA: The Effect of an Unjust Evolution of the Urban Landscape on Urban Heat Islands. Sustainability 2021, 13, 1511. https:// doi.org/10.3390/su13031511

Academic Editor: Troy Abel Received: 28 October 2020

Accepted: 28 January 2021

Published: 1 February 2021

Publisher's Note: MDPI stays neutral with regard to jurisdictional claims in published maps and institutional affiliations.

Copyright: (c) 2021 by the authors. Licensee MDPI, Basel, Switzerland. This article is an open access article distributed under the terms and conditions of the Creative Commons Attribution (CC BY) license (https:// creativecommons.org/licenses/by/ $4.0 /)$.
Abstract: The urban heat island (UHI) effect is caused by intensive development practices in cities and the diminished presence of green space that results. The evolution of these phenomena has occurred over many decades. In many cities, historic zoning and redlining practices barred Black and minority groups from moving into predominately white areas and obtaining financial resources, a practice that still affects cities today, and has forced these already disadvantaged groups to live in some of the hottest areas. In this study, we used a new dataset on the spatial distribution of temperature during a heat wave in Richmond, Virginia to investigate potential associations between extreme heat and current and historical demographic, socioeconomic, and land use factors. We assessed these data at the census block level to determine if blocks with large differences in temperature also had significant variation in these covariates. The amount of canopy cover, percent impervious surface, and poverty level were all shown to be strong correlates of UHI when analyzed in conjunction with afternoon temperatures. We also found strong associations of historical policies and planning decisions with temperature using data from the University of Richmond's Digital Scholarship Lab's "Mapping Inequality" project. Finally, the Church Hill area of the city provided an interesting case study due to recent data suggesting the area's gentrification. Differences in demographics, socioeconomic factors, and UHI were observed between north and (more gentrified) south Church Hill. Both in Church Hill and in Richmond overall, our research found that areas occupied by people of low socioeconomic status or minority groups disproportionately experienced extreme heat and corresponding impacts on health and quality of life.

Keywords: urban heat islands; socioeconomic inequity; temperature; poverty; redlining; race

\section{Introduction}

Warming attributable to human emissions of heat-trapping gases is unequivocal [1] At the planetary scale, observable trends include decreased snow and ice cover, changes in phenology/growing seasons, droughts, and some aspects of hurricane formation, strength, and translational speed [2]. The consequences on human health and well-being are dire. As the climate warms, typical weather patterns become more extreme. This includes an increase in heavy rain during monsoon season, followed by an extremely hot dry period, which can result in severe human and economic losses [3]. The changes in atmospheric conditions also affect heat, the deadliest weather hazard in the United States. Death from heat and related drought make up $19.6 \%$ of all natural hazard deaths in the U.S.; severe summer weather is a close second at $18.8 \%$ [4]. The frequency, duration, and intensity of heat waves across the U.S. have all increased over the past 50 years [5]. These changes are accentuated in cities through urban heat island (UHI) effects.

An urban heat island is an area of a city that is consistently warmer, in terms of surface temperature, air temperature, or both, than its suburban and rural surroundings [6]. UHIs 
result from increased land surface temperature (LST) as heat energy gets trapped on the Earth's surface [7]. This is often caused by highly intense development, from industrial areas to dense mixed-use city centers, along with the removal of green space [8,9]. Urban areas, as a result, have a high net radiation retention due to their generally low albedo, poor thermal dissipation, and emissions of heat and heat-trapping pollutants [10]. Trees and other vegetation reduce the amount of radiation that reaches and is retained in the ground, lowering surface temperatures and mitigating UHI effects as a whole [11]. Ziter et al. showed that temperature decreased with increasing canopy cover, with the greatest cooling effects when canopy cover surpassed 40\% [12]. Unfortunately, racial minorities and communities of low socioeconomic status suffer disproportionately from UHI in the United States, which is compounded by lack of access to central air conditioning in their homes or public refuge facilities $[13,14]$. This distribution of at-risk populations stems in large part from the historical practices of exclusionary zoning and redlining [15].

Throughout the 20th century, public and private sectors around the U.S. used several different tactics to exclude minority groups from certain neighborhoods. Redlining occurred when people living in an area classified as having a poor financial status were refused a financial resource, such as a loan or insurance. These policies served to uphold segregation by denying resources either directly based on race or indirectly based on historical proxies for race, such as one's neighborhood, financial status, health conditions, and insurance history [16]. This racially biased policy has historically been an issue in cities throughout the U.S. and has resulted in Black and other minority residents getting trapped in the cycle of poverty, a pattern of segregation that is still visible in many U.S. cities today [17]. As early as 1910, Baltimore became the first city to create outright racial zoning laws. Richmond followed suit and in 1911 passed their own segregation law that banned Black households from moving into white household blocks and vice-versa. In 1917, the Supreme Court case Buchanan v. Warley banned these racial zoning codes, declaring city-mandated racial zoning unconstitutional [18].

In response to the decision in Buchanan v. Warley, which specifically dealt with municipal legal statutes, the racial restrictive covenant became a common practice. This entailed the buyer of a house entering into a written agreement with the seller promising not to sell, rent, or transfer the property to "any person not of the Caucasian race" and specifically "against the occupancy as owners or tenants of any portion of said property for resident or other purposed by people of the Negro or Mongolian race" [19] (p. 5). In 1937, the federal Home Owners' Loan Corporation (HOLC) began assessing perceived risk in major U.S. cities. Their goal was to determine what areas would be more likely to pay off their amortized home loans. These designations are what later led to the practice of redlining [20]. By 1940, 80 percent of both Chicago and Los Angeles carried restrictive covenants barring Black families [20]. The long-lasting effects of these policies on many U.S. cities are well documented, but the specific negative implications on environmental conditions, such as temperature resulting from discrimination against and segregation of Black communities, require further exploration.

Hoffman et al. [21] described how the areas that experience the highest surface temperatures in cities like Richmond and Baltimore correlate significantly with historic redlining. HOLC map shapefiles for 108 US cities or urban areas were compared to land surface temperatures (LSTs) derived from Landsat 8 imagery collected between 3 June 2014 and 25 August 2017. Mean LST within each HOLC security polygon was estimated, yielding the ability to show on average how much cooler or warmer a single HOLC security polygon is in comparison to all of the HOLC security polygons overall. The resulting non-uniform distribution in LST differences across various cities demonstrates that present-day urban heat is influenced by historical policies. In general, cities that have experienced redlining tend to be warmer overall than those that have not experienced redlining [21].

Our study builds on this work by investigating in further depth whether increased heat in certain areas of Richmond, Virginia is associated with the history of those areas and current demographic factors, especially those related to race and socioeconomic status. We 
explore the history of the city, including its history of redlining that created legacy spatial patterns in the demographics of the city, and we analyze more recent demographic change over the past decade including ongoing impacts of gentrification and immigration. We then consider how these changing demographics are related to the distribution of temperature in the city. Our goal is to assess which populations of the city may be most at risk from extreme heat and to evaluate the historical and contemporary drivers of these patterns.

\section{Materials and Methods}

\subsection{Study Area}

Richmond, Virginia provides a history of segregation over lines of race, ethnicity, and class, which has had a lasting footprint on the modern landscape. As of 2018, Richmond has an area of $162.056 \mathrm{~km}^{2}$ and an estimated population of 230,436. According to American Community Survey 5-year estimates (2014-2018), Richmond's racial makeup is 48\% Black, $45 \%$ White, $2 \%$ Asian, and 5\% other, with 7\% of Richmond residents identifying ethnically as Hispanic or Latino [22]. The majority of the white populations reside near the more suburban West End, while the vast majority of the Black populations are located on the east side of the city, which is denser and more urban. Additionally, the Latino populations tend to reside in the southern parts of Richmond, near the Chesterfield border (Figure 1). Race and class are heavily intertwined in Richmond: those areas with the highest median household income and lowest poverty are in the mostly white West End while the areas with low income and high poverty are in the mostly Black East End. Although the Black population accounted for $48 \%$ of the population in 2018 , they accounted for $65 \%$ of those in poverty. Richmond's poverty rate of $24.5 \%$ in 2018 was much higher than both Virginia $(10.9 \%)$ and the U.S. (14.1\%); the median household income in Richmond $(\$ 45,117)$ was significantly lower than that of Virginia $(\$ 71,564)$ and the U.S. $(\$ 60,293)$ in 2018 (Figure 2).

\section{Race and Ethnicity in Richmond, 2018}

\section{Percent Black Alone Overall: $48 \%$}

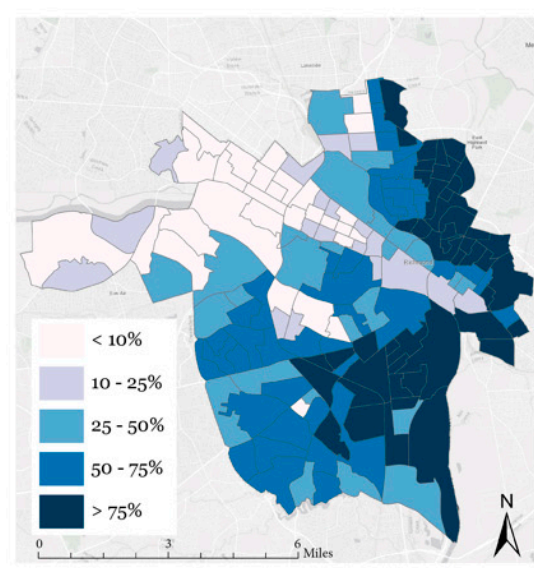

Percent Hispanic Overall: $7 \%$

\section{Percent Non-Hispanic White Overall: $45 \%$}

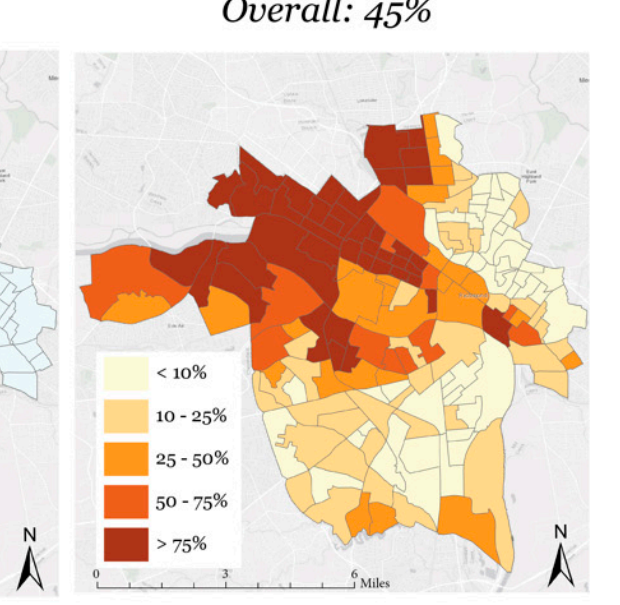

Figure 1. Race and ethnicity distribution in Richmond, VA. Source: American Community Survey (ACS) 5-year estimates (2014-2018).

Because of Richmond's unique development history, the urban form varies throughout the city. According to 2016 data from the Multi-Resolution Land Characteristics Consortium National Land Cover Database (NLCD) [23], 77.2\% of Richmond's land cover is impervious surfaces. The abundance of developed surfaces in the eastern part of the city is evident in Figure 3. The southeast includes the highest concentration of industrial land uses. In contrast, much of the one-third of the city's area that is classified as single-family housing can be found in the western extents of the city (Figure 3) [24]. The racial, ethnic, and socioeconomic diversity, as well as vast differences in urban form throughout different areas 
of the city, allowed for in-depth analyses of potential relationships between temperature and a variety of demographic and geographic factors associated with the marginalization of certain urban populations.

\section{Economic Outcomes in Richmond, 2018}

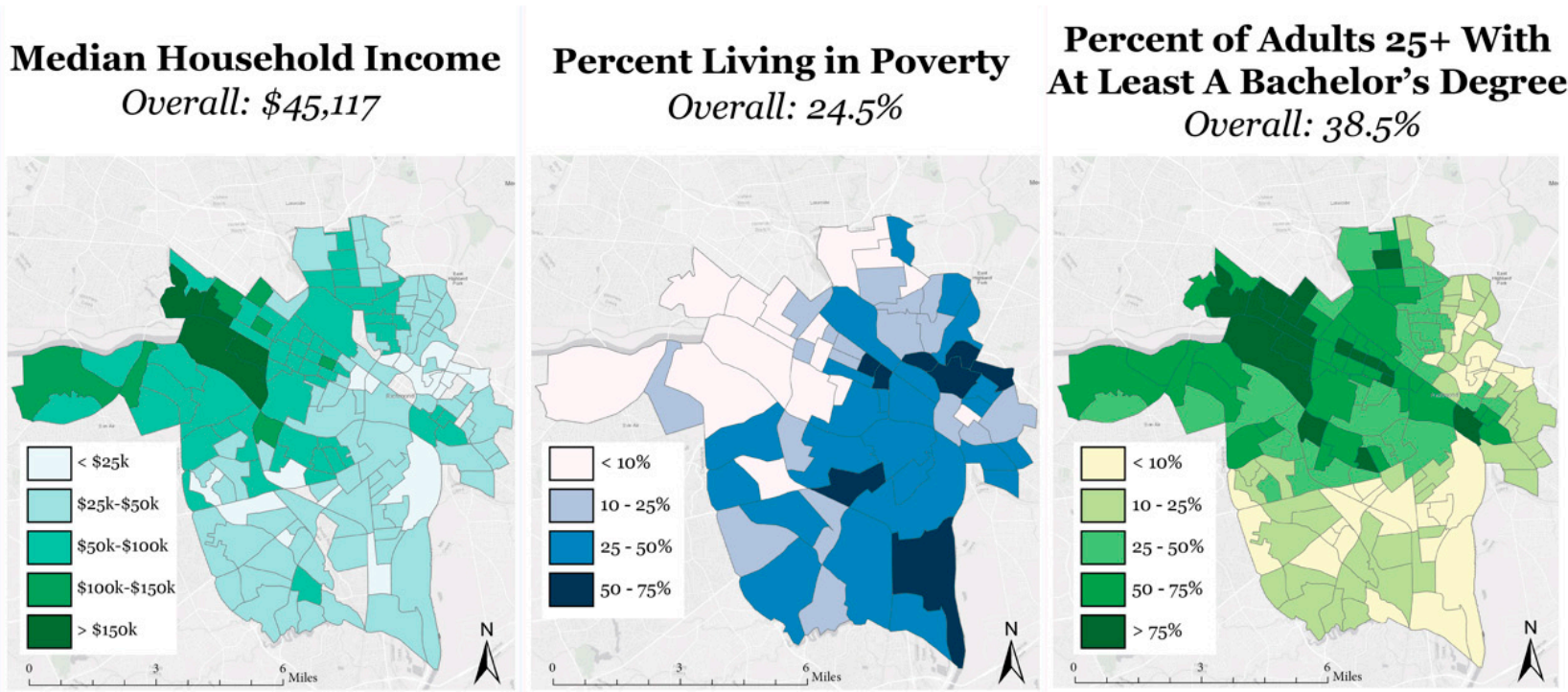

Figure 2. Economic indicators in Richmond, VA, including median household income, poverty, and educational attainment. Source: ACS 5-year estimates (2014-2018).

\section{Land Use and Land Cover in Richmond}

Land Use (2018)

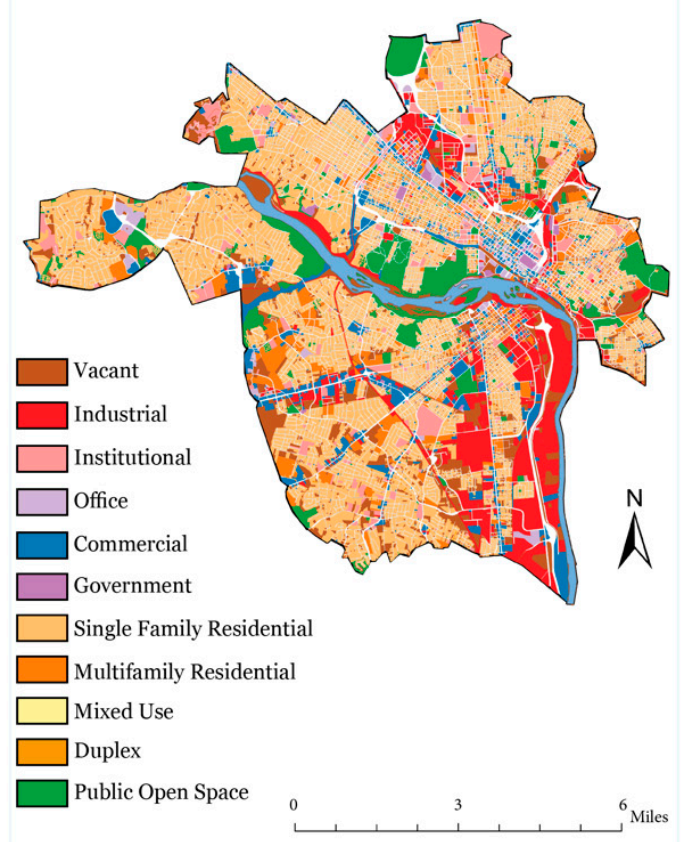

Land Cover (2016)

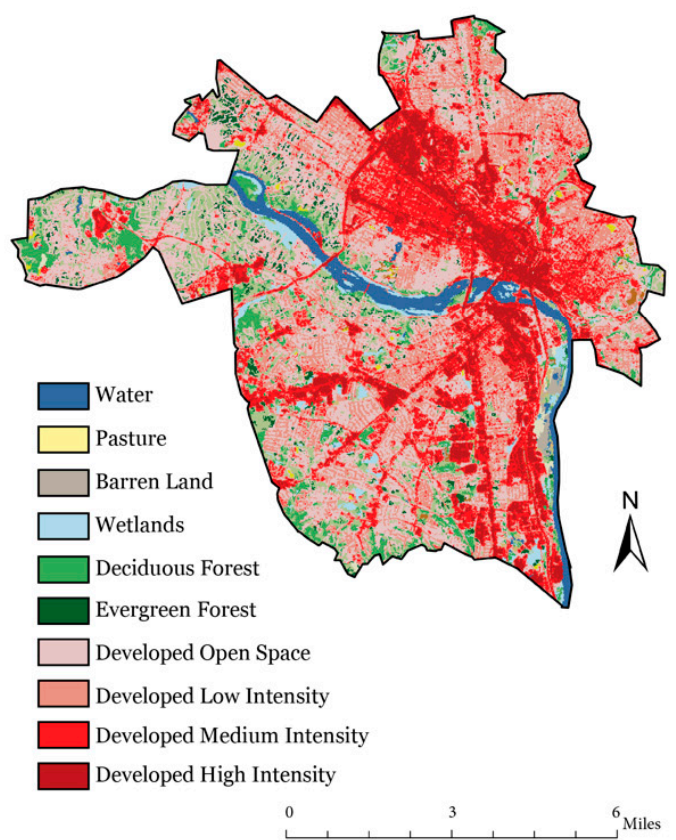

Figure 3. Land use and land cover in Richmond, VA. Sources: Richmond Planning and Development Review and National Land Cover Database. 
The socioeconomic and racial divisions evident in Richmond today are a continuing legacy of zoning codes established nearly one hundred years ago. In the late 1930s, Harland Bartholomew, a St. Louis-based planner who was hired to create a city plan and begin the annexation of some of wealthiest areas in neighboring Henrico County, asserted that one of the greatest "deficiencies" of Richmond's 1927 zoning code was "the lack of single-family residential districts," since "the soundest realty values in any city" are owner-occupied single-family dwellings [25] (p. 6). Bartholomew's solution to this socalled problem was a new zoning ordinance based on socioeconomic status and increased housing type designation of Richmond's neighborhoods. This forced families who could not afford single-family housing out of these designated areas and prevented others from moving in, a practice that became known as economic zoning. Because race and class are so intertwined, single-family districts would avert non-white, mainly Black, and poor individuals from moving into these districts, creating wealthy, white neighborhoods in areas deemed 'most desirable' or Grade A. The new ordinance was adopted in 1942 with minimal backlash, since zoning was a novel planning tool and its format was too complicated for the average person to understand [25].

The results of the 1942 zoning ordinance showed a clear difference in treatment between majority-white and majority-Black neighborhoods. The most notable change from the 1927 zoning ordinance was the division from just three residential districts into three single-family, one two-family, and two multiple-family residential districts. In overlaying the "Negro Areas" map from Bartholomew's master plan with the 1942 zoning map, none of the Black areas became zoned "A" or "B" Single Family; just a handful of Black areas in the Northside, the East End, and Manchester were zoned " $C$ " Single Family, but the majority were either in " $\mathrm{D}$ " Two-Family, " $\mathrm{E}$ " or " $\mathrm{F}$ " Multiple Family, or even in "J" Light Industrial or " $K$ " Heavy Industrial Districts (Figure 4). Because of the link between race and class, the implication was that the poor, Black residents could not afford to live in the exclusive, white, single-family enclaves. This was intensified by the use of restrictive covenants to prevent Black families from moving into homes, as well as the refusal of banks to make home loans to those households due to redlining [13]. Consequently, these factors led to Black families continuing to live in the smaller, older, and less expensive homes in the less 'prestigious' residential districts.

The zoning ordinance was also problematic in that it placed many predominantly Black areas in or adjacent to industrial districts, including Scott's Addition, Manchester, and Shockoe Bottom. According to Richard Rothstein, "the racial aspect of" the choice to zone industrial areas close to Black neighborhoods "was a desire to avoid the deterioration of white neighborhoods when African American sites were available alternatives ... the welfare of African Americans did not count for much in this policy making" [20] (p. 55). Through the 1942 zoning ordinance, the City was able to insulate and "protect" the wealthy and white neighborhoods. After decades of these segregation tactics, the poorest citizens, who were disproportionately people of color, were left practically unable to move anywhere beyond inner cities. Disinvestment toward the poor inner-city communities through the mid-20th century left a stark contrast between the majority-Black areas and the majority-white areas [26]. These socioeconomic and racial contrasts still exist today in Richmond, and we therefore predict that these long-term inequities, coupled with physical differences in the city's landscape, will result in more Black communities located in the hottest areas of the city, causing them to be most affected by the urban heat island effect and its negative repercussions. 


\section{Racial Implications of 1942 Zoning Ordinance in Richmond}
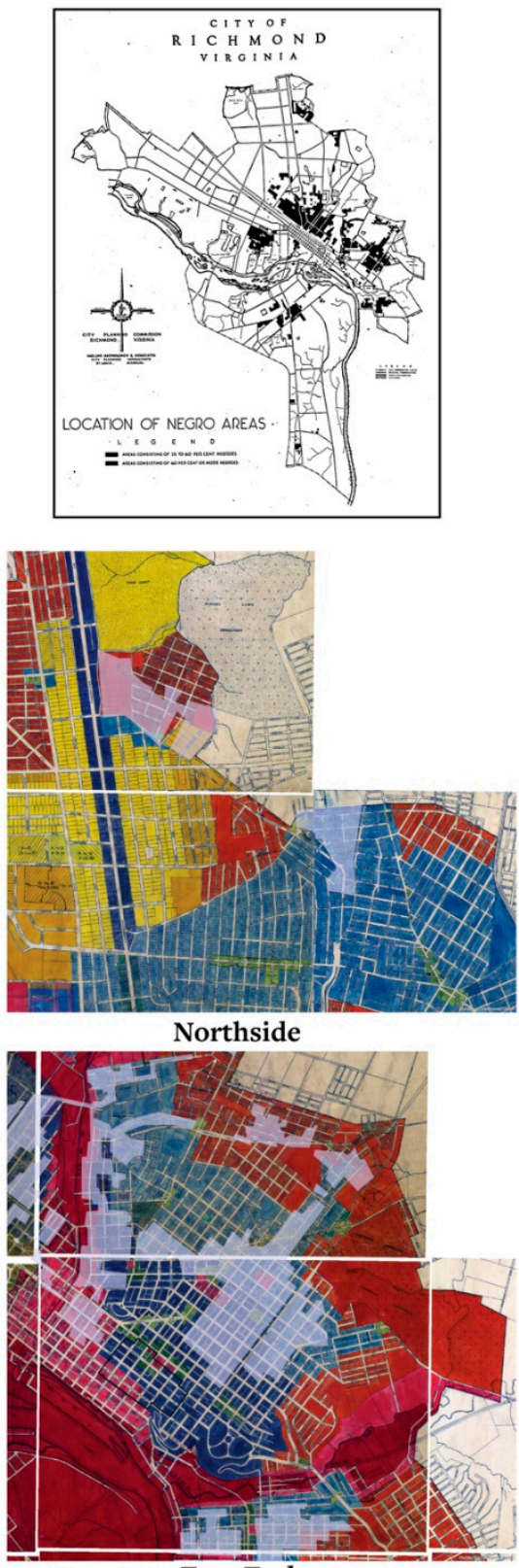

East End
Areas with black population $>25 \%$ from Bartholomew's 1942 "Location of Negro Areas" map

"A" Single Family Residence District

"B" Single Family Residence District

"G" Single Family Residence District

“D” Two-Family Dwelling District

"E” Multiple Family Dwelling District

"F" Multiple Family Dwelling District

"G" Local Business District

"H" Commercial District

"I" General Business District

"J" Light Industrial District

"K" Heavy Industrial District
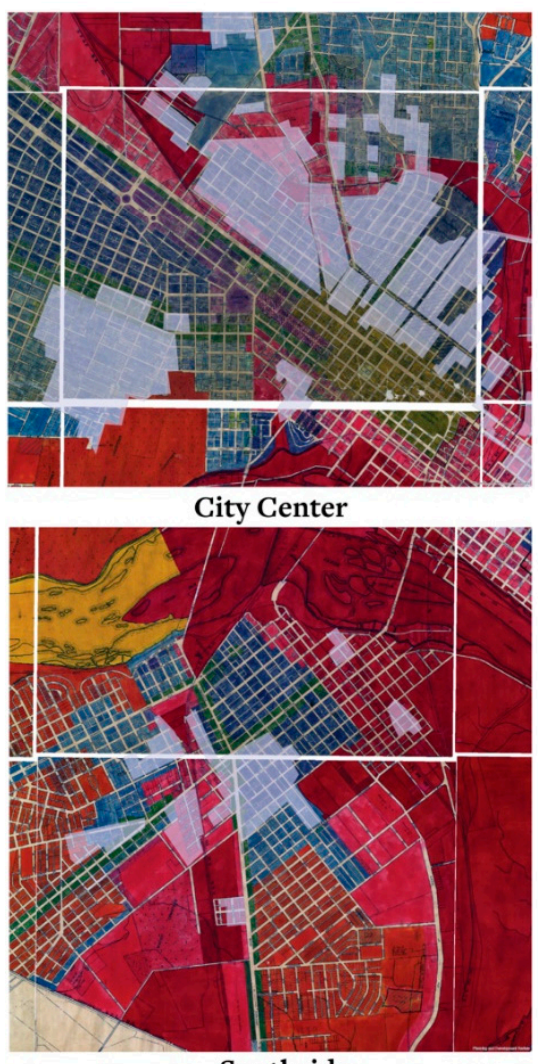

Southside

Figure 4. Zoning categories in Richmond, VA that resulted from the 1942 zoning ordinance and areas with greater than 25\% Black population in 1940. Source: Richmond Planning and Development Review.

\subsection{Data}

The spatial distribution of temperature in the City of Richmond is derived from a field sample conducted on 13 July 2017. On this day, one of the hottest of the summer, teams of researchers, students, and volunteers walked, biked (three bicycles), or drove (nine cars) throughout 12 areas of the city with vehicle-mounted sensors that recorded their spatial coordinates at one-second intervals and corresponding afternoon (3:00-4:00 p.m.) temperature using a type " $\mathrm{T}$ " thermocouple and data logger [27]. The tens of thousands of observations generated were then fed into a machine learning algorithm to model temperature at $10-\mathrm{m}^{2}$ resolution based on the associations between these observations and spectral data from the Sentinel-2 satellite constellation [27]. A full description of the temperature data collection, quality assurance, and modeling is available in Shandas et al., 
2019 [27]. Our study relates to Shandas et al., 2019 by expanding on their urban heat island location prediction technique to determine if the hottest areas of Richmond, VA are occupied by certain socioeconomic, racial, or ethnic groups. The temperature map was then aggregated by census block groups [28] using ArcGIS Pro and areas of extreme high temperature were classified as urban heat islands (Figure 5).

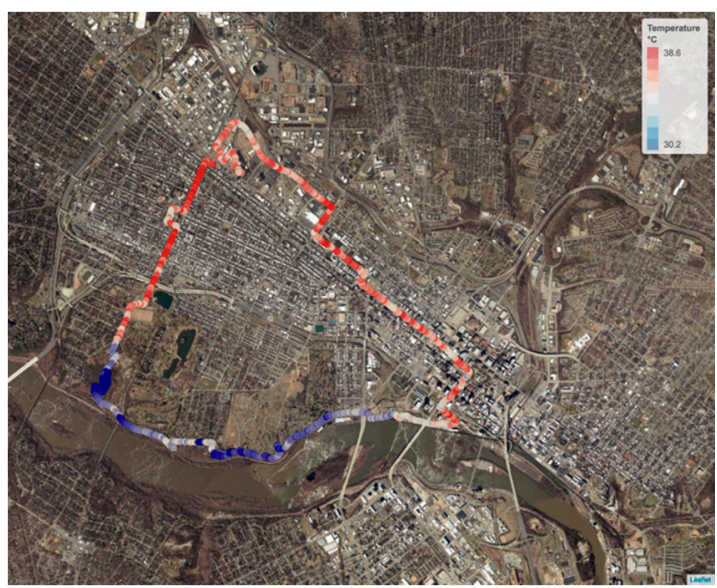

Afternoon Mean Temperature, July 2017
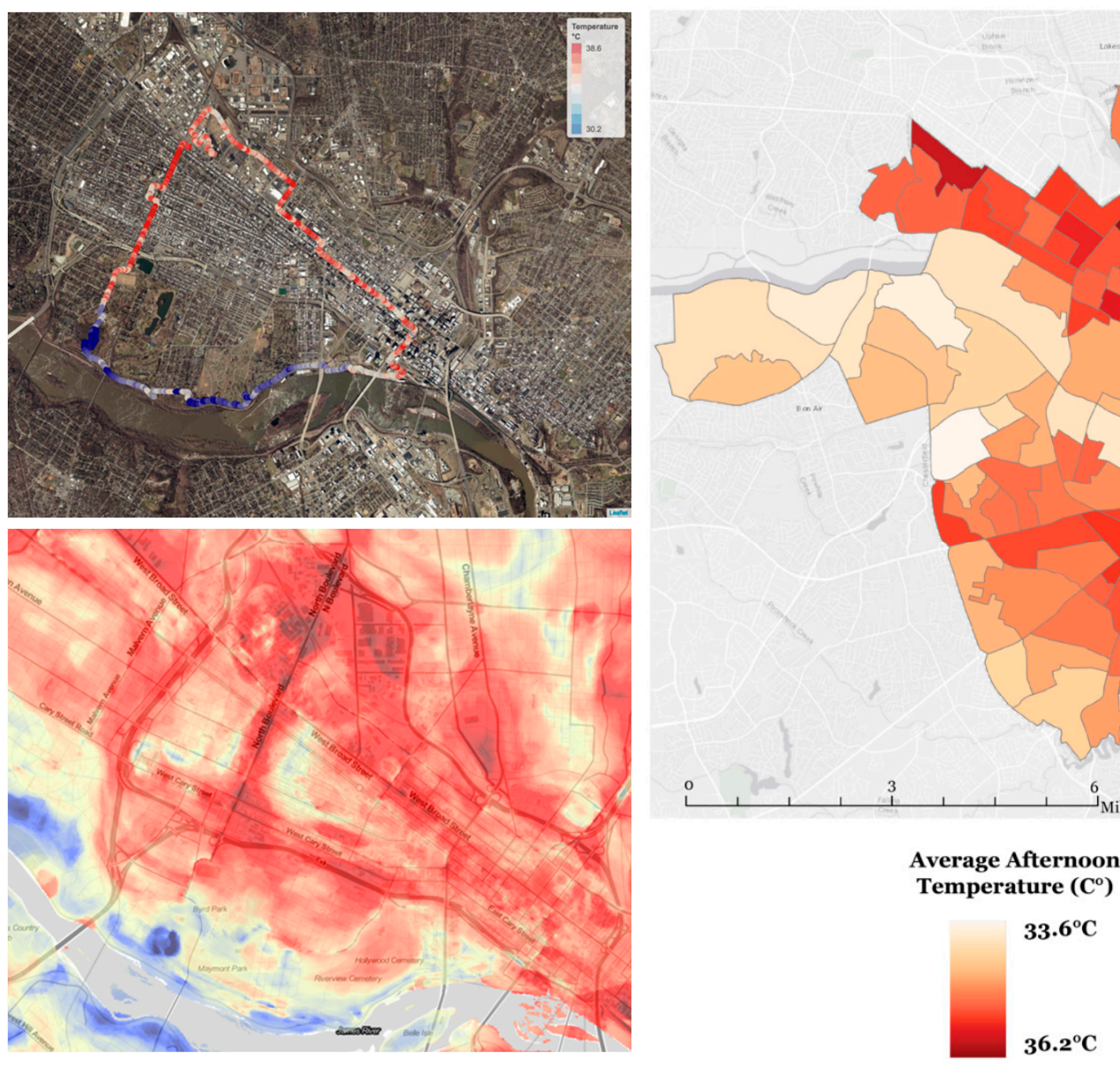

Figure 5. Average afternoon temperature by census block group in Richmond, VA in July 2017. Images on the left provide an example of how data from one of the bike-route transects was used to create the temperature model for the city. Values from the temperature model were then aggregated by census block. Source: Shandas et al., 2019.

Impervious surface and canopy cover data were retrieved from the National Land Cover Database (NLCD) [23]. Green space data were sourced from an ArcGIS map of parks and open space created for the Richmond 300 Master Plan [29]. The "parks and open space" layer used to represent green space encompasses recognized parks, sports fields, farmer's markets, community gardens, cemeteries, and other vegetated areas. These maps were overlaid with a map of Richmond's census blocks [28] using ArcGIS Pro, and the percentage of each census block comprising impervious surface, canopy cover, and green space was calculated (Figure 6). 


\section{Public Greenspace, Impervious Surfaces, and Canopy Cover}

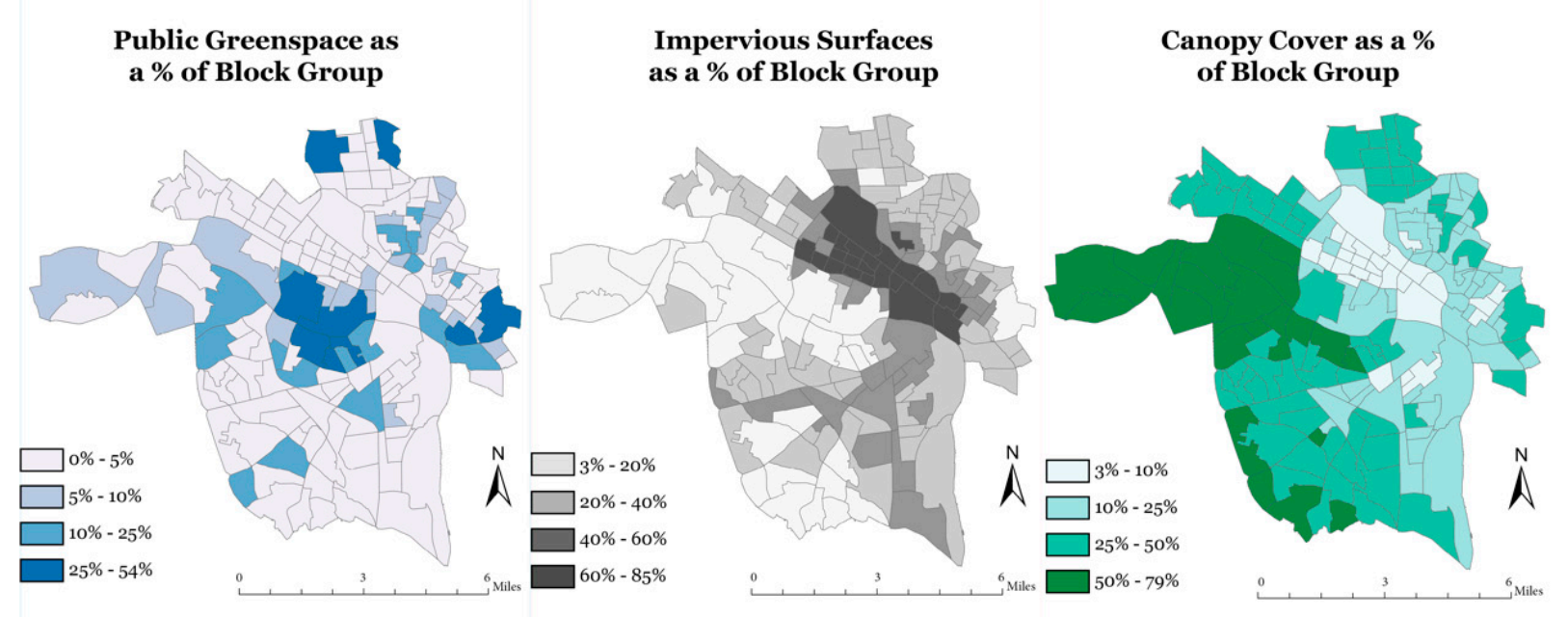

Figure 6. Greenspace, impervious surface, and canopy cover as percentages of census block group.

Redlining data were obtained from the "Mapping Inequality" database of the University of Richmond's Digital Scholarship Lab [30], with the city divided into polygons designated by one of four HOLC security ratings: $A=$ Best, $B=$ Still Desirable, $C=$ Definitely Declining, $\mathrm{D}=$ Hazardous. The security ratings were meant to indicate the residential desirability of a neighborhood, as well as the "threat of infiltration of foreign-born, negro, or lower-grade population" [30]. The proportion within each census block of each HOLC rating was calculated. In subsequent analyses, Grade A "Best" and Grade B "Still Desirable" sections were combined, while Grade C "Definitely Declining" and Grade D "Hazardous" sections were combined.

Demographic data were collected to assess any associations between demographic factors and temperature data. We aggregated data from American Community Survey's (ACS) most recent 5-year estimates (2014-2018) at the block group level [31]. We collected data for the following attributes: total population (table A00001), race and ethnicity (tables A03001 and A04001), household income (table A14006), highest educational attainment (table A12002), transportation to work for workers 16 years and older (table A09005), poverty status in 2018 (tables A13003A, A13003B, and A13003C), per capita income (table A14024), and number of housing units in each structure (table A10032). Race and ethnicity were normalized as a percent of the total population. For highest educational attainment, we used the number of adults over 25 years old with at least a bachelor's degree normalized as a percent of total population.

All data were gathered to be representative of the 2014-2018 range to be consistent with the 5-year ACS estimates. Temperature data represent July 2017. NLCD data used to extract impervious surface and canopy cover were derived from the 2016 dataset. Green space data represents 2017 and was sourced from the Richmond Planning and Development Office. The only exception is the redlining data, which was included to assess the legacy effects of historical policy. To examine trends in the demographic data, we also collected the 5-year ACS estimates from 2010 data (2006-2010) [32].

\subsection{Analysis}

To identify areas of the city with high and low values for a given variable, we first divided the city into quartiles based on our 16 chosen predictor variables. For example, the first quartile (Q1) blocks based on household income had an average median household income of $\$ 22,615$ and the highest quartile (Q4) blocks had an average median household income of $\$ 98,945$; the Q1 blocks based on white population had an average of $7.9 \%$ of the population identifying as white, while the Q4 blocks had, on average, $89.3 \%$ of the population of the blocks identifying as white. 
Then, to assess if the predictor variable had a significant correlation with temperature (i.e., low household income blocks were associated with increased temperatures) we conducted t-tests on the temperature data, grouping the census blocks by Q1 and Q4 for the variable of interest. For example, we asked whether the set of census blocks with a median household income of $\$ 22,615$ (Q1) was significantly warmer than the set of census blocks with a median household income of $\$ 98,945(\mathrm{Q} 4)$. We repeated these tests for all 16 predictor variables to determine which variables had the strongest relationship with temperature. Determining what factors were most strongly associated with temperature differences allowed us to look at what populations of the city are most at risk. By mapping all the variables, we were able to identify which portions of the city had the greatest risks.

To determine the possible influence of gentrification, we looked at temporal patterns between temperature and demographic factors from the ACS data (from 2010 to 2018). We identified three areas of the city with large changes in highest educational attainment, which we used as an indicator of gentrification: Church Hill, Manchester, and Scott's Addition (Figure 7).

\section{Changes in Educational Attainment in Richmond, 2010-2018}

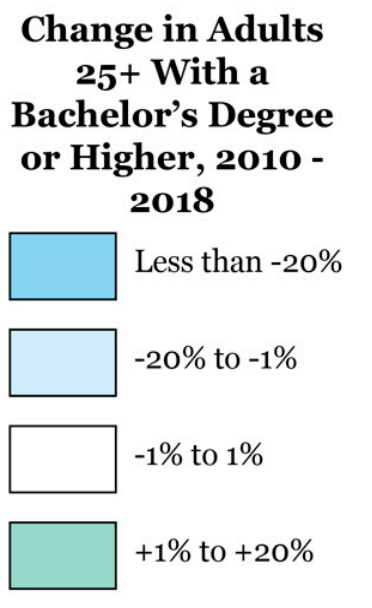

Greater than $+20 \%$

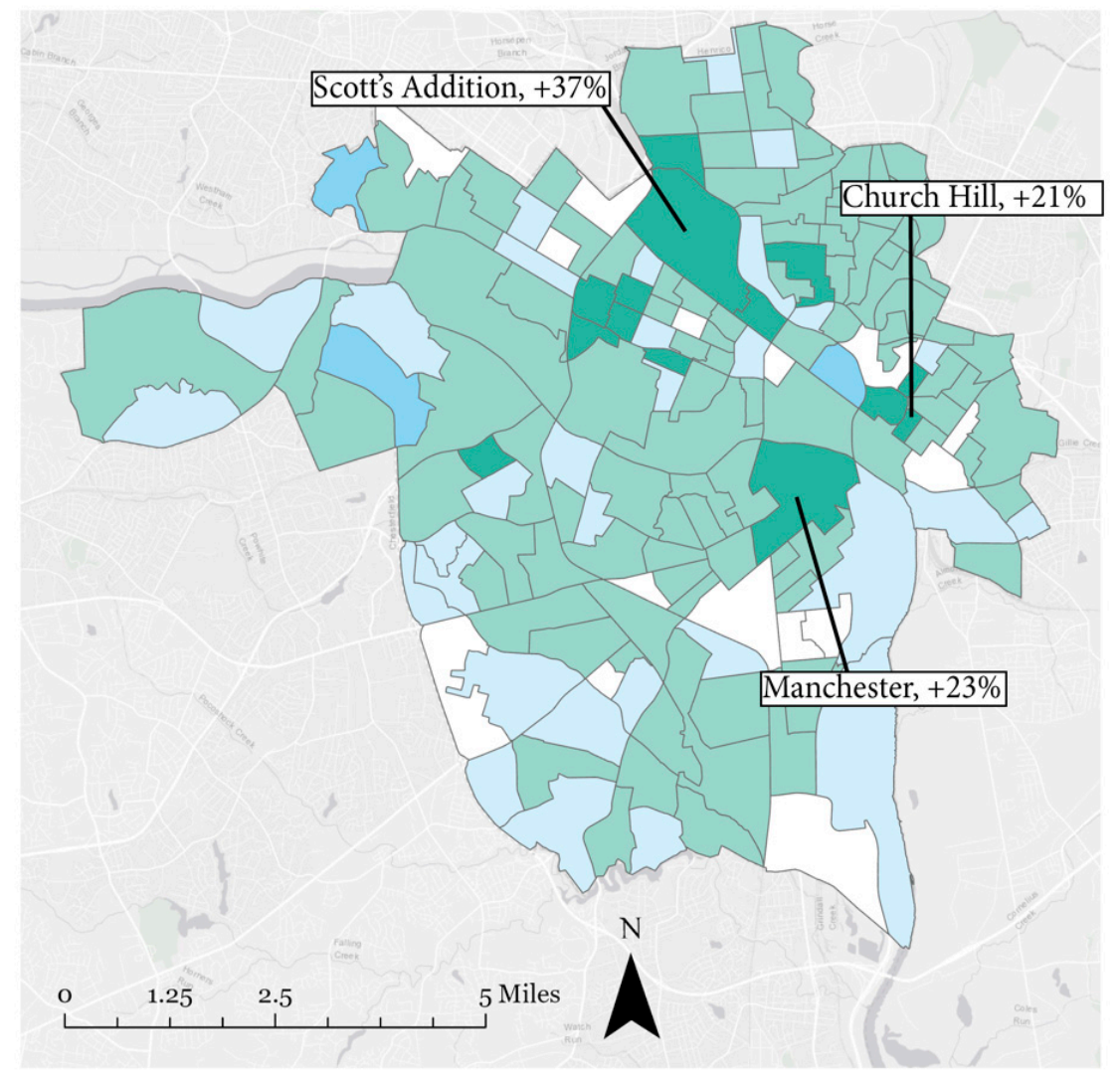

Figure 7. Changes in educational attainment between 2010 and 2018 by census blocks in Richmond, VA. Educational attainment in this case is defined as adults age 25 or older with a bachelor's degree or higher. Source: ACS 5-year estimates (2014-2018).

\section{Results}

Mapping the temperature data from Shandas et al. [27] throughout Richmond provides evidence that heat is unequally distributed throughout the city. General spatial discrepancies emerge. The most urban, downtown areas and areas toward the eastern side of the city were significantly hotter than the more suburban parts of Richmond. The hottest areas of the city included Scott's Addition, Manchester, and Church Hill. In contrast, 
areas in the western part of the city, especially those with higher tree cover south of the river, were considerably cooler. Sites of extreme heat included areas that were historically redlined. The distribution of HOLC security ratings throughout Richmond, as well as their corresponding average afternoon temperatures, can be seen in Figure 8. The importance of this historical policy in determining the trajectory of landscape evolution leading to disparities in urban heating is evident from the overlap of the two data layers.

\section{Average Afternoon Temperature vs. 1937 Home Owners' Loan Corporation Risk Ratings}
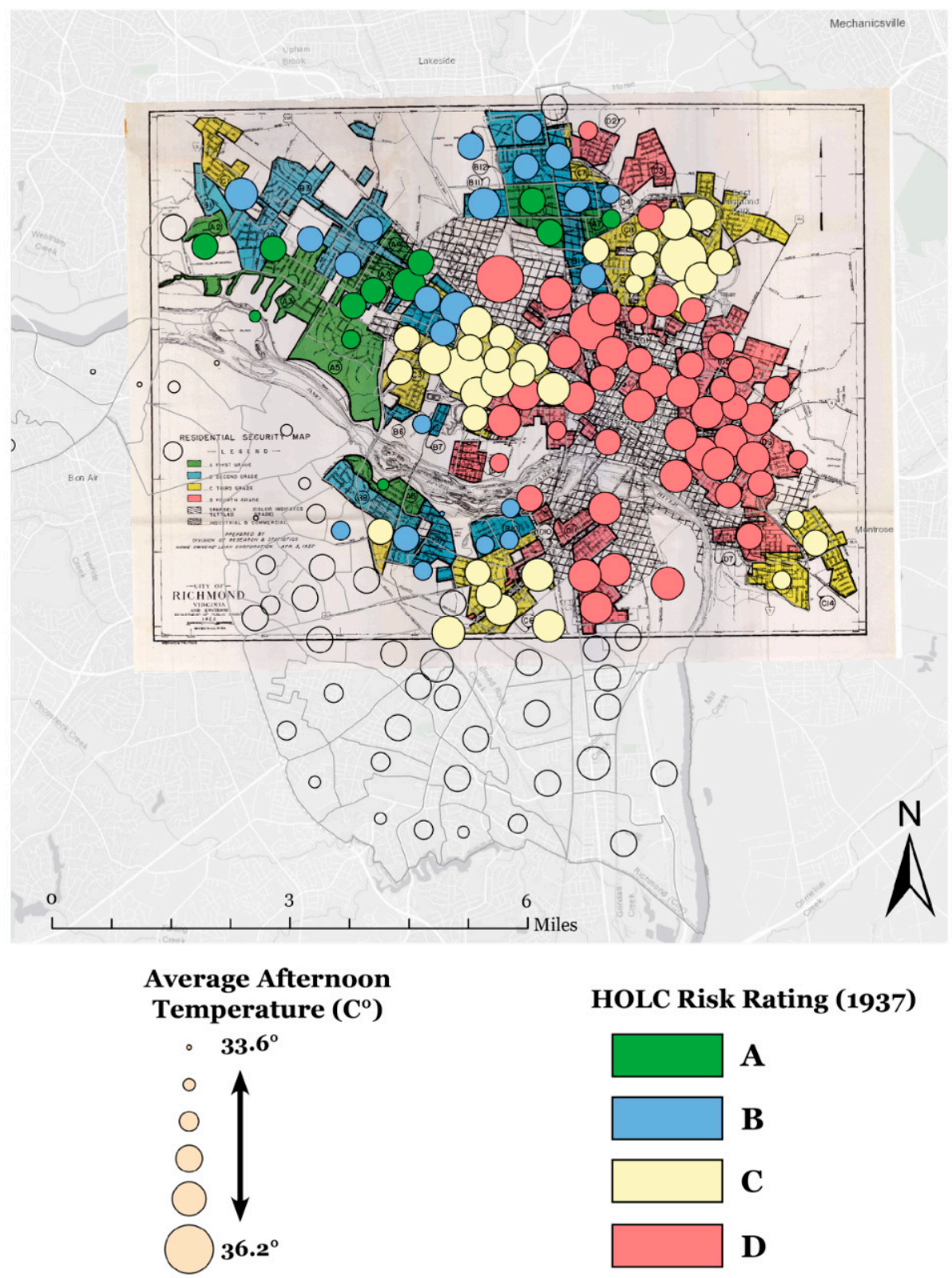

Figure 8. 1937 Home Owners' Loan Corporation (HOLC) risk ratings throughout Richmond, VA. Average afternoon temperature is overlaid, with larger circles indicating higher temperatures. Sources: Shandas et al., 2019 and Home Owners' Loan Corporation, Division of Research and Statistics (3 April 1937).

We determined that a variety of social-environmental factors were associated with temperature (Table 1). A total of 10 of the 16 social-environmental factors were associated with statistically significant differences in afternoon temperature according to the $\mathrm{t}$-tests 
$(p<0.01)$. At a significance level of $p<0.05,14$ out of 16 of the variables had a significant association with temperature. The top six strongest variables associated with temperature were percent impervious surface, percent canopy cover, percent of the block that was redlined Category C or D, percent drove alone to work, median household income, and percent below poverty level (Figure 9). The strong associations between temperature and Category C or D redlining, public transportation use, and low median household income suggest that the poorest neighborhoods were indeed the hottest. Percent impervious surface and percent canopy cover, the two strongest variables associated with temperature, each have a Q4-Q1 temperature difference with an absolute value of about $1{ }^{\circ} \mathrm{C}$. This difference of $1{ }^{\circ} \mathrm{C}$ is about equal to the entirety of warming that the Earth has experienced since pre-industrial times, and the impacts of this warming on the planet have been welldocumented $[2,3]$.

We were interested in further exploring the variation between racial groups due to Richmond's history of redlining and racial division, despite their absence among the six most significant variables. Black communities and those living below the poverty line were disproportionately located in the hottest areas of Richmond and in turn exposed to the negative consequences of the heat, compared to their wealthier, white counterparts (Figure 10). Again, there was a clear east-west divide that can be traced back to historical housing policies.

Table 1. Quartile analyses of the 16 variables associated with afternoon temperature.

\begin{tabular}{|c|c|c|c|c|}
\hline Variable & Q1 Average & Q4 Average & $\begin{array}{c}\text { Temperature Difference } \\
{ }^{\circ} \mathrm{C}(\mathrm{Q} 4-\mathrm{Q} 1)\end{array}$ & $\begin{array}{c}t \text {-Test } \\
p \text {-Value }\end{array}$ \\
\hline Impervious surface (\%) & 17.38 & 52.71 & 1.01 & $3.18 \times 10^{-19}$ \\
\hline Canopy cover $(\%)$ & 13.76 & 47.87 & -0.96 & $1.36 \times 10^{-18}$ \\
\hline Redlining C + D (\%) & 0 & 83.79 & 0.53 & $3.15 \times 10^{-6}$ \\
\hline Drove alone to work (\%) & 47.5 & 88.13 & -0.51 & $4.27 \times 10^{-6}$ \\
\hline Below poverty level (\%) & 18.21 & 30.98 & 0.51 & 0.0015 \\
\hline Median household income (\$) & 22,615 & 98,945 & -0.41 & 0.0008 \\
\hline Per capita income $(\$)$ & 11,293 & 57,490 & -0.37 & 0.002 \\
\hline White population (\%) & 7.6 & 89.31 & -0.31 & 0.007 \\
\hline Detached housing (\%) & 12.31 & 93.13 & -0.31 & 0.009 \\
\hline Green space (\%) & 0 & 17.81 & -0.3 & 0.0097 \\
\hline Black population (\%) & 6.09 & 86.9 & 0.27 & 0.0156 \\
\hline Redlining A + B (\%) & 0 & 55.53 & -0.26 & 0.011 \\
\hline Non-Hispanic white population (\%) & 2.43 & 88.46 & -0.26 & 0.0158 \\
\hline Attached housing $(\%)$ & 0 & 20.07 & 0.25 & 0.024 \\
\hline Bachelor's degree or more (\%) & 6.108 & 74.6 & -0.11 & 0.248 \\
\hline Hispanic population (\%) & 0.056 & 19.2 & 0.09 & 0.378 \\
\hline
\end{tabular}

Variables were sourced from the 2018 American Community Survey (ACS), the 2016 National Land Cover Database (NLCD), 2017 green space data from the Richmond Planning and Development Office, and historical 1937 data on redlining from the Home Owners' Loan Corporation, Division of Research and Statistics. The table lists variables from most to least significant. Q1 and Q4 averages indicate the average value of the variable within those quartiles. The temperature difference $\left({ }^{\circ} \mathrm{C}\right)$ shows the heat difference between the $\mathrm{Q} 1$ average temperature and the Q4 average temperature. Positive values indicate that Q4 blocks are warmer than Q1 blocks and negative values indicate that Q1 blocks are warmer than Q4 blocks. 
Strongest Variables Associated With Afternoon Temperature vs. Average Afternoon Temperature

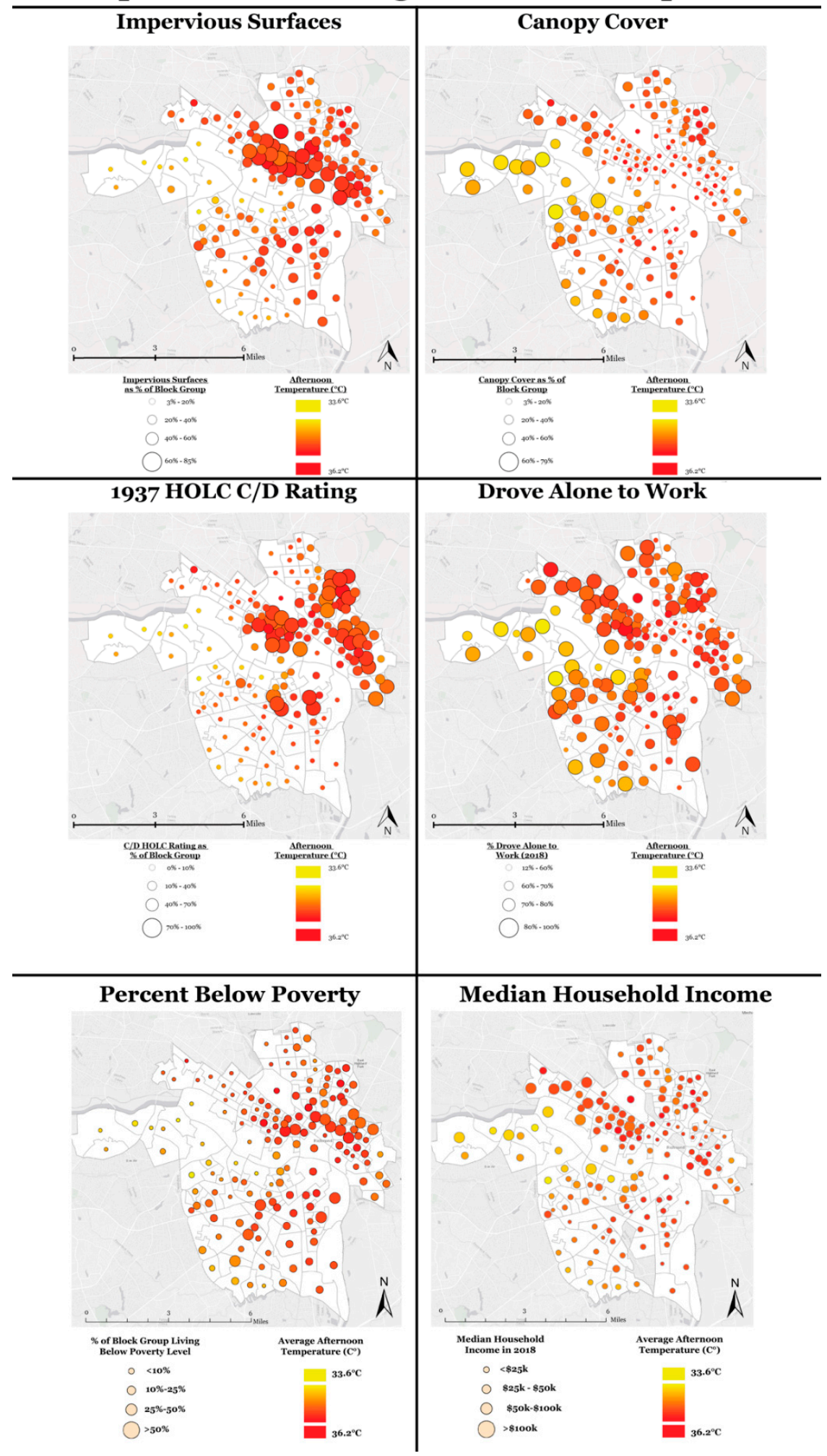

Figure 9. Comparison of variables associated with average afternoon temperature throughout Richmond, VA. Percent impervious surface, percent canopy cover, percent of a block rated Category $\mathrm{C}$ or $\mathrm{D}$, percent drove alone to work, percent below the poverty level, and median household income produced some of the strongest associations with afternoon temperature. 


\section{Prevalence of Race vs. Average Afternoon Temperature}
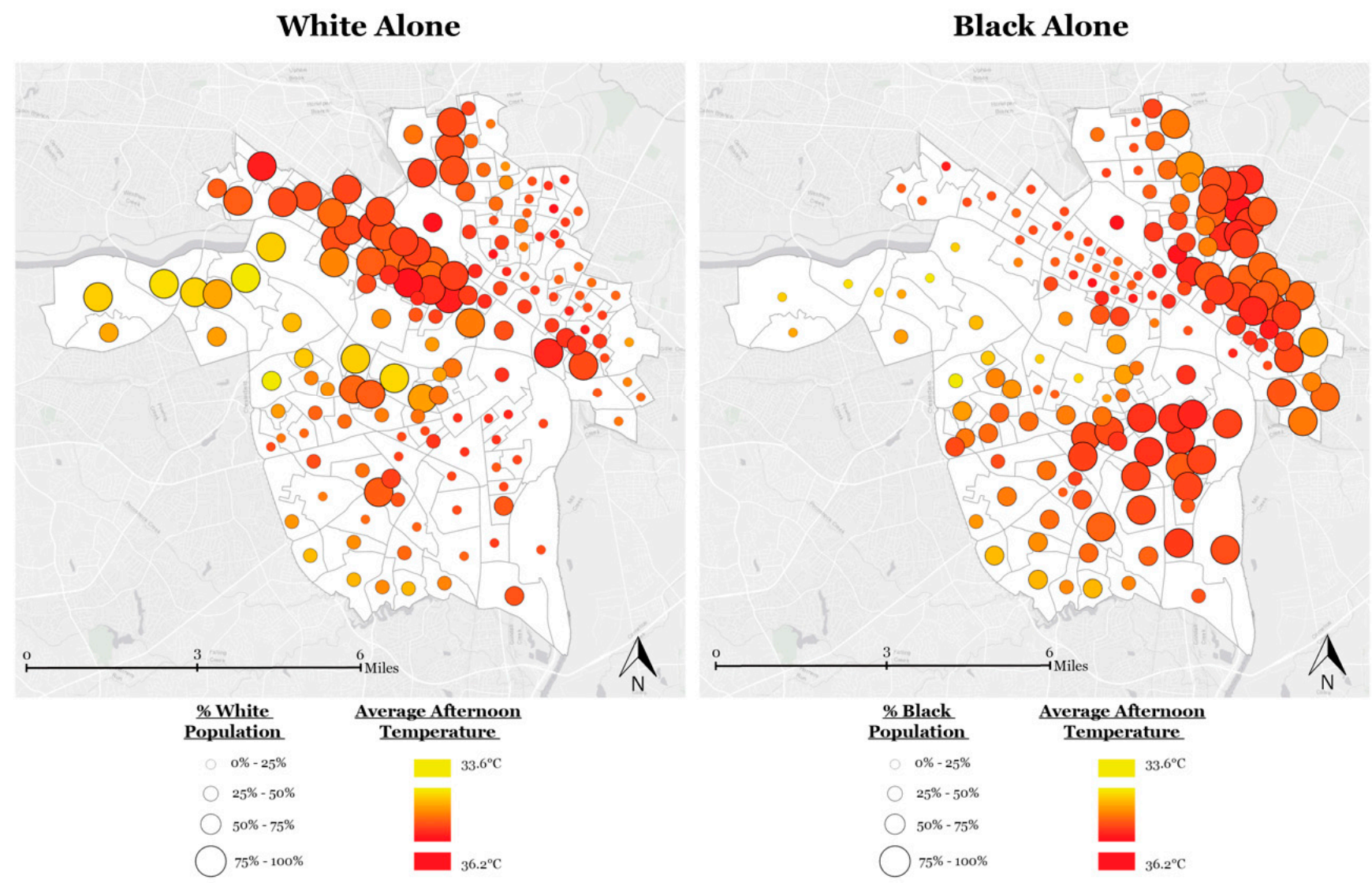

Figure 10. Distribution of white and Black populations throughout Richmond, VA, compared to the average afternoon temperature. In each map, the larger the circle is, the greater the population of the corresponding race. The White Alone map indicates that the greatest portion of white residents live toward the western end of the city, while the Black Alone map indicates that the greatest portion of Black residents live toward the eastern end.

To evaluate the changes in the aforementioned variables over time, American Census Data from 2010 was analyzed and compared to 2018 data. In 2010, the two strongest variables associated with afternoon temperature were median household income and percent drove alone to work (Table 2). This was consistent with our 2018 analyses, in which these two variables also had the strongest associations with temperature. The magnitude of the temperature differences between the Q1 and Q4 neighborhoods were also similar between 2010 and 2018 at around $0.5^{\circ} \mathrm{C}$. Four out of the seven demographic variables analyzed for 2010 had a significant relationship with temperature at a significance level of $p<0.01$ and an additional two variables were significant at a level of $p<0.05$. The 2010 variables were only sourced from ACS data and did not include the redlining or land use and land cover variables. 
Table 2. Quartile analyses of the seven variables associated with afternoon temperature from the 2010 American Community Survey (ACS), ordered from most to least significant.

\begin{tabular}{ccccc}
\hline Variable & Q1 Average & Q4 Average & $\begin{array}{c}\text { Temperature Difference } \\
{ }^{\circ} \text { C (Q4-Q1) }\end{array}$ & $\begin{array}{c}t \text {-Test } \\
\boldsymbol{~ - V a l u e ~}\end{array}$ \\
\hline Median household income (\$) & 19,046 & 80,909 & -0.5 & $1.72 \times 10^{-5}$ \\
\hline Drove alone to work (\%) & 46.12 & 88.77 & -0.46 & 0.0001 \\
\hline Non-Hispanic white population (\%) & 4.6 & 87.81 & -0.33 & 0.0038 \\
\hline Bachelor's degree or more (\%) & 2.94 & 72.88 & -0.29 & 0.0106 \\
\hline White population (\%) & 3.28 & 90.24 & -0.28 & 0.0091 \\
\hline Black population (\%) & 5.44 & 93.64 & 0.26 & 0.0124 \\
\hline Hispanic population (\%) & 0 & 14.95 & 0.09 & 0.4284 \\
\hline
\end{tabular}

Q1 and Q4 averages indicate the average value of the variable within those quartiles. The temperature difference $\left({ }^{\circ} \mathrm{C}\right)$ shows the heat difference between the Q1 average temperature and the Q4 average temperature. Positive values indicate that Q4 blocks are warmer than Q1 blocks and negative values indicate that Q1 blocks are warmer than Q4 blocks.

Notable changes occurred in the demographic data from 2010 to 2018. For example, the difference between Q1 and Q4 median household income in 2010 was $\$ 61,863$, while the difference in 2018 was $\$ 76,330$. This shows a $\$ 14,467$ increase in the disparity between the median household incomes of the richest and poorest areas of Richmond within the eightyear period. This disparity is driven, in part, by pockets of gentrification in the city. One example is South Church Hill, which experienced an increase in median household income of $\$ 7517$ from 2010 to 2018. During that same period, North Church Hill experienced little to no gentrification. Demographic patterns between these two adjacent neighborhoods are typical of gentrification, with more minority groups, Black and Hispanic populations, and those of lower socioeconomic status in the north (Table 3). We hypothesized that the gentrified South Church Hill (Blocks 206 East and West) would have a lower mean afternoon temperature than North Church Hill (Block 207), perhaps due to green space increase or albedo-related land use changes. However, the data did not show a significant difference in temperature. This suggests that historical factors, including redlining, still primarily determine temperature rather than more recent demographic change.

Table 3. Comparison of temperature, socioeconomic, and demographic data between North and South Church Hill.

\begin{tabular}{cccc}
\hline Variable & South (206 East) & South (206 West) & North (207) \\
\hline Mean afternoon temperature $\left({ }^{\circ} \mathrm{C}\right)$ & 35.69 & 35.7 & 35.96 \\
\hline Below poverty level $(\%)$ & 8.3 & 15.67 & 39.27 \\
\hline Per capita income $(\$)$ & 40,508 & 37,757 & 17,104 \\
\hline Median household income $(\$)$ & 66,620 & 45,673 & 22,135 \\
\hline White population $(\%)$ & 48.46 & 73.11 & 17.1 \\
\hline Black population $(\%)$ & 34.46 & 19.34 & 75.52 \\
\hline Redlining Category D $(\%)$ & 67.8 & 38.37 & 56.89 \\
\hline Property value $(\$)$ & 232,000 & 229,950 & 129,888 \\
\hline
\end{tabular}

South Church Hill is divided into two census blocks, since both the eastern and western blocks that comprise the area are included.

\section{Discussion}

The main goal of this study was to determine if there was any correlation between the hottest areas of the city and certain demographic, socioeconomic, and land use factors. Percent impervious surface and percent canopy cover were determined to be the two 
strongest variables associated with afternoon temperature, meaning that the higher the proportion of impervious surfaces or the less canopy cover an area has, the warmer the area is likely to be. These factors have direct mechanistic influences on temperature, and the strength of these observed associations was not surprising. The next four strongest correlates each were associated with approximately $0.5^{\circ} \mathrm{C}$ in temperature difference and included a variety of social and historical factors including the redlining HOLC security ratings of the census blocks.

Our results are representative of national patterns showing the lingering effects of redlining. In a related study, redlined communities were found to be hotter than nonredlined neighbors in $94 \%$ of the 108 U.S. cities studied [21]. This extreme heat, in turn, poses a significant threat in terms of adverse health effects for the communities living there [33]. One group that is highly impacted is pregnant women, specifically Black women, living within urban heat islands [34-36]. In a meta-analysis conducted to evaluate the association between heat exposure and birth issues, it was found that the chance of a premature birth increases by $11.6 \%$ for every $5.6^{\circ} \mathrm{C}$ increase in temperature [37]. As climate change inevitably worsens over the coming years, such issues will be exacerbated.

Planting trees has the opportunity to address the inequity in heat in many cities, and cities across the planet have pledged to plant millions of trees to contribute to this effort. Programs like the Trillion Trees Initiative (https: / / trilliontrees.org/) have begun to emphasize the importance of urban forests where trees provide multiple values including reducing urban heat island effects, fighting pollution, reducing flooding, and sequestering carbon $[38,39]$. The benefits already provided by existing trees in urban communities include approximately $\$ 7.8$ billion in savings from reduced heating and cooling of residential buildings [40]. In the case of minimal space for tree planting, increasing vegetative cover, such as on roofs, has also been found to aid in cooling [10]. Our study points to the need to concentrate future planting in specific neighborhoods to reduce current inequities in urban heating [37].

Richmond is one of the cities that would greatly benefit from mass tree planting and other efforts to mitigate heat [41]. In recent planning initiatives, including the Office of Sustainability's RVAgreen 2050 and Richmond's most recent 20-year plan [42], there has been notable attention paid to UHI and climate issues. RVAgreen 2050 is the City of Richmond's "equity-centered climate action and resilience planning initiative to achieve net zero greenhouse gas emissions by 2050 and help the community adapt to Richmond's climate impacts of extreme heat, precipitation, and flooding" [43] (paragraph 1). The city plans to address urban heat by using light-colored pavement to reflect sunlight, varying building heights in hot neighborhoods to increase air flow, protecting and restoring natural resources, increasing tree shade on sidewalks, and ensuring that every Richmond resident lives within a ten-minute walk of a park [42]. Though the goal is to implement these improvements throughout the entirety of the city, the main and initial focus will be on the hottest and poorest neighborhoods of Richmond.

Additional benefits of these proposed improvements to the physical environment include a variety of health benefits. Green urban planning has the potential to reduce mental illness within vulnerable populations [44], who tend to be those living in the hottest areas of the city. These mental health concerns span from everyday stress to more serious psychiatric disorders like schizophrenia. In a study of 943,027 residents of Denmark, Engemann et al. [44] found that the risk of developing a psychiatric disorder between adolescence and adulthood was reduced by up to $55 \%$ when childhood development took place in a relatively green area. The association between improved mental health and ample green space was still evident when controlling for socio-economic status, urbanization, and family history of mental conditions, all known predictors of psychiatric disorders.

The hottest areas of the city in our study tend to correspond to historically redlined regions as has been documented for many cities of the U.S. [21]. Church Hill, an area of Richmond located in the northeast part of the city, is one of these regions. The southern part of Church Hill has been gentrified while the north has not. In the 1950s, Broad Street 
was the dividing line between north and south. However, as gentrification spreads north, the present-day border has moved to $\mathrm{N}$ Street, which aligns with the census block divide. Yet, we do not yet see differences in temperature among the different neighborhoods in Church Hill, suggesting historical factors continue to have an outsized influence on current temperatures in cities.

Going forward, it would be beneficial to repeat our data collection to look for any progression or changes within the predictor variables and their relationship to temperature. Performing additional case studies, like the Church Hill analyses, could be useful in evaluating the effects of redlining on other areas known to have experienced gentrification. Further analysis of Scott's Addition would be an interesting extension since the greatest change in educational attainment from 2010 to 2018, our indicator of gentrification, was found here. The area was dominated by industrialization starting in the early 20th century when the land was annexed to the City of Richmond [45], but has become Richmond's fastest growing neighborhood in recent years [46]. Due to a call for more residential development in the late 20th century, Scott's Addition now includes a variety of breweries, restaurants, and apartment complexes [45]. Currently, the 6505-strong population of Scott's Addition consists of $87.2 \%$ white collar workers and only $12.8 \%$ blue collar workers. Households are predominately non-family households without children [47]. As factories made way for new businesses, younger people with more education and higher incomes (average household income: $\$ 73,488$ [47]) were drawn to the area, contributing to the change in educational attainment over time. Similar patterns can be found in other gentrified regions as well, as wealthier people and businesses move into these areas. It is yet to be seen whether these socioeconomic changes will translate to reductions in thermal stress.

We also stress that our analysis relies on a series of bivariate comparisons to determine the associations between the demographic and land use variables with temperature. Of course, there are interactions among many of the variables, and future analyses would benefit from the inclusion of longer time series data and more robust multivariate analyses.

\section{Conclusions}

Based on our research it is evident that heat is unequally distributed throughout the City of Richmond. This is the result of racist historical zoning practices that sought to keep white neighborhoods separate from Black and minority communities and protected from the harm of industrialization. The extremely detrimental effects of these practices are still evident in the segregation of Richmond today, as the more affluent suburban western end of the city is dominated by white neighborhoods and the urban eastern side of the city is dominated by Black neighborhoods. Since areas occupied by Black communities were essentially sacrificed as industrialization grew, these regions have the most impervious surfaces and least green space and are in turn the warmest parts of the city. In comparison, the western end of the city has a great deal of green space and minimal impervious surfaces. At local scales, differences in temperature were expected between adjacent gentrified and non-gentrified regions. The temperature data comparing North Church Hill and gentrified South Church Hill were not significant, yet the two areas did have large differences in percent below the poverty level, per capita income, median household income, and property value, revealing the tangible effects of gentrification. While the extent of the disparity that the findings revealed is disturbing, the data can be used to implement initiatives to reduce the thermal imbalance.

The findings of this study can be used to improve city planning, such as increasing green space in areas that currently lack access. Construction in areas known to be the hottest can incorporate heat mitigating tactics. Light-colored or vegetated roofs are one such strategy to minimize heat absorption. Working to improve heat inequality in Richmond will not only be advantageous to the environment, but also has the potential to greatly improve health inequity among racial and ethnic groups and people of varying socioeconomic statuses throughout the city. 
Author Contributions: Conceptualization, K.C.S., T.R.L. and A.M.E.; methodology, K.C.S. and T.R.L.; software, K.C.S.; validation, K.C.S., T.R.L., E.R., J.S.H. and A.M.E.; formal analysis, K.C.S.; investigation, K.C.S., E.R., T.R.L., A.M.E., J.S.H. and R.B.; resources, K.C.S., E.R., T.R.L., J.S.H. and R.B.; data curation, K.C.S., E.R. and R.B.; writing-original draft preparation, K.C.S., E.R. and T.R.L.; writing-review and editing, K.C.S., E.R., T.R.L., A.M.E. and J.S.H.; visualization, K.C.S., E.R., T.R.L. and R.B.; supervision, T.R.L.; project administration, K.C.S. and T.R.L.; funding acquisition, K.C.S., T.R.L. and J.S.H. All authors have read and agreed to the published version of the manuscript.

Funding: This research was funded by the University of Richmond IQS Summer Fellowship Grant and Science Museum of Virginia support from the Virginia Academy of Science Small Research Grant Program. J.S.H. acknowledges further funding support from the NOAA Office of Education Award NA15SEC0080009.

Institutional Review Board Statement: Not applicable.

Informed Consent Statement: Not applicable.

Data Availability Statement: Not applicable.

Acknowledgments: We thank our colleagues at the University of Richmond's Spatial Analysis Lab, Digital Scholarship Lab, and Unpacking the Census Project for their support in developing background datasets for this study.

Conflicts of Interest: The authors declare no conflict of interest. The funders had no role in the design of the study; in the collection, analyses, or interpretation of data; in the writing of the manuscript, or in the decision to publish the results.

\section{References}

1. IPCC. Climate Change 2014: Synthesis Report. Contribution of Working Groups I, II and III to the Fifth Assessment Report of the Intergovernmental Panel on Climate Change; Core Writing Team, Pachauri, R.K., Meyer, L.A., Eds.; IPCC: Geneva, Switzerland, 2014; p. 151.

2. NASA. Facts: The Effects of Climate Change. Available online: https:/ / climate.nasa.gov / effects/ (accessed on 25 November 2020).

3. Wang, S.S.-Y.; Kim, H.; Coumou, D.; Yoon, J.-H.; Zhao, L.; Gillies, R.R. Consecutive Extreme Flooding and Heat Wave in Japan: Are They Becoming a Norm? Atmos. Sci. Lett. 2019, 20. [CrossRef]

4. Borden, K.A.; Cutter, S.L. Spatial patterns of natural hazards mortality in the United States. Int. J. Health Geogr. 2008, 7. [CrossRef] [PubMed]

5. Habeeb, D.; Vargo, J.; Stone, B., Jr. Rising Heat Wave Trends in Large US Cities. Nat. Hazards 2015, 76, 1651-1665. [CrossRef]

6. Arnfield, A.J. two decades of urban climate research: A review of turbulence, exchanges of energy and water, and the urban heat island. Int. J. Climatol. 2003, 23, 1-26. [CrossRef]

7. Kimuku, C.W.; Ngigi, M. Study of urban heat island trends to aid urban planning in Nakuru County-Kenya. J. Geogr. Inf. Syst. 2017, 9, 309-325. [CrossRef]

8. Chakraborty, T.; Hsu, A.; Manya, D.; Sheriff, G. A Spatially Explicit Surface Urban Heat Island Database for the United States: Characterization, Uncertainties, and Possible Applications. ISPRS J. Photogramm. Remote Sens. 2020, 168, 74-88. [CrossRef]

9. Livesley, S.J.; Mcpherson, E.G.; Calfapietra, C. The urban forest and ecosystem services: Impacts on urban water, heat, and pollution cycles at the tree, street, and city scale. J. Environ. Qual. 2016, 45, 119-124. [CrossRef]

10. Solecki, W.D.; Rosenzweig, C.; Parshall, L.; Pope, G.; Clark, M.; Cox, J.; Wiencke, M. Mitigation of the heat island effect in urban New Jersey. Environ. Hazards 2005, 6, 39-49. [CrossRef]

11. Farina, A. Exploring the Relationship between Land Surface Temperature and Vegetation Abundance for Urban Heat Island Mitigation in Seville, Spain. Master's Thesis, Lund University, Lund, Sweden, 2012.

12. Ziter, C.D.; Pederson, E.J.; Kucharik, C.J.; Turner, M.G. Scale-dependent interactions between tree canopy cover and impervious surfaces reduce daytime urban heat during summer. Proc. Natl. Acad. Sci. USA 2019, 116, 7575-7580. [CrossRef]

13. Wilson, B. Urban heat management and the legacy of redlining. J. Am. Plan. Assoc. 2020, 86, 443-457. [CrossRef]

14. Voelkel, J.; Hellman, D.; Sakuma, R.; Shandas, V. Assessing vulnerability to urban heat: A study of disproportionate heat exposure and access to refuge by socio-demographic status in Portland, Oregon. Int. J. Environ. Res. Public Health 2018, 15, 640. [CrossRef] [PubMed]

15. Jones-Correa, M. The origins and diffusion of racial restrictive covenants. Political Sci. Q. 2000, 115, 541-568. [CrossRef]

16. Hillier, A.E. Redlining and the home owners' loan corporation. J. Urban Hist. 2003, 29, 394-420. [CrossRef]

17. Mitchell, B.; Franco, J. HOLC "Redlining" Maps: The Persistent Structure of Segregation and Economic Inequality; National Community Reinvestment Coalition (NCRC): Washington, DC, USA, 2018; pp. 1-29.

18. Manning Thomas, J.; Ritzdorf, M. (Eds.) The Racial Origins of Zoning in American Cities. In Urban Planning and the African Community: In the Shadows; Sage Publications: Thousand Oaks, CA, USA, 1997. 
19. United States Commission on Civil Rights (USCCR). Understanding Fair Housing; Government Printing Office: Washington, DC, USA, 1973; p. 5.

20. Rothstein, R. The Color of Law: A Forgotten History of How Our Government Segregated America; Liveright Publishing Corporation A Division of W. W. Norton \& Company: New York, NY, USA, 2017.

21. Hoffman, J.S.; Shandas, V.; Pendleton, N. The Effects of Historical Housing Policies on Resident Exposure to Intra-Urban Heat: A Study of 108 US Urban Areas. Climate 2020, 8, 12. [CrossRef]

22. U.S. Census Bureau QuickFacts: Richmond City, Virginia; United States. Available online: https:/ /www.census.gov/quickfacts / richmondcityvirginia (accessed on 15 August 2020).

23. Homer, C.; Dewitz, J.; Yang, L.; Jin, S.; Danielson, P.; Xian, G.; Coulston, J.; Herold, N.; Wickham, J.; Megown, K. Completion of the 2011 national land cover database for the conterminous United States-Representing a decade of land cover change information. Photogramm. Eng. Remote Sens. 2015, 81, 345-354.

24. Richmond Planning and Development Review Department. "Richmond 300 Insights Report". 2017. Available online: http: //richmond300.com/sites/default/files/InsightsReport_Sept2018_180906.pdf (accessed on 2 September 2020).

25. Richmond Times-Dispatch; NewsBank, Inc.: Richmond, VA, USA, 1942; p. 6.

26. Summers, B.T. Capital Reinvestment: Riot, Renewal, and the Rise of a Black Ghetto. In Black in Place: The Spatial Aesthetics of Race in a Post-Chocolate City; The University of North Carolina Press: Chapel Hill, CA, USA, 2019; pp. $28-60$.

27. Shandas, V.; Voelkel, J.; Williams, J.; Hoffman, J. Integrating Satellite and Ground Measurements for Predicting Locations of Extreme Urban Heat. Climate 2019, 7, 5. [CrossRef]

28. 2010 Census Blocks Map RVA. Available online: https://www2.census.gov/geo/maps/dc10map/tract/st51_va/c51760 _richmond_city/DC10CT_C51760_001.pdf (accessed on 6 August 2020).

29. ArcGIS Parks and Open Space. Available online: http:/ / www.arcgis.com/home/webmap/viewer.html?webmap=879f1b39d175 4e2f80d7b35a747622b6 (accessed on 6 August 2020).

30. Nelson, R.K. Race and Redlining in Richmond. Redlining Richmond n.d. Available online: https://dsl.richmond.edu/holc/ pages/intro (accessed on 1 October 2020).

31. American Community Survey (ACS) 5-Year Estimates 2014-2018. Available online: http:/ / data.census.gov/ (accessed on 28 July 2020).

32. American Community Survey (ACS) 5-Year Estimates 2006-2010. Available online: http:/ / data.census.gov/ (accessed on 28 July 2020).

33. Nardone, A.; Chiang, J.; Corburn, J. Historic redlining and urban health today in U.S. Cities. Environ. Justice 2020, 13, 109-119. [CrossRef]

34. Smith, M.L.; Hardeman, R.R. Association of summer heat waves and the probability of preterm birth in minnesota: An exploration of the intersection of race and education. Int. J. Environ. Res. Public Health 2020, 17, 6391. [CrossRef]

35. Nardone, A.L.; Casey, J.A.; Rudolph, D.E.; Karasek, D.; Mujahid, M.; Morello-Frosch, R. Associations between historical redlining and birth outcomes from 2006 through 2015 in California. PLoS ONE 2020, 15. [CrossRef]

36. Krieger, N.; Van Wye, G.; Huynh, M.; Waterman, P.D.; Maduro, G.; Li, W.H.; Gwynn, R.C.; Barbot, O.; Bassett, M.T. Structural Racism, Historical Redlining, and Risk of Preterm Birth in New York City, 2013-2017. Am. J. Public Health 2020, 110, 1046-1053. [CrossRef]

37. Bekkar, B.; Pacheco, S.; Basu, R.; DeNicola, N. Association of air pollution and heat exposure with preterm birth, low birth weight, and stillbirth in the US: A Systematic Review. JAMA Netw. Open 2020, 3, e208243. [CrossRef] [PubMed]

38. Domkea, G.M.; Oswaltb, S.N.; Waltersa, B.F.; Morinc, R.S. Tree planting has the potential to increase carbon sequestration capacity of forests in the United States. Proc. Natl. Acad. Sci. USA 2020, 117, 24649-24651. [CrossRef] [PubMed]

39. Brancalion, P.H.S.; Holl, K.D. Guidance for successful tree planting initiatives. J. Appl. Ecol. 2020, 57, 2349-2361. [CrossRef]

40. Nowak, D.J.; Appleton, N.; Ellis, A.; Greenfield, E. Residential building energy conservation and avoided power plant emissions by urban and community trees in the United States. Urban For. Urban Green. 2017, 21, 158-165. [CrossRef]

41. Boycourt, L.A. Richmond Tree Initiative to Combat Heat, Pollution, Inequity. Available online: https:// chesapeakebaymagazine. $\mathrm{com} /$ richmond-tree-initiative-to-combat-heat-pollution-inequity/ (accessed on 29 November 2020).

42. Richmond Planning and Development Review Department. "Richmond 300: A Guide for Growth". June 2020. Available online: http: / / www.richmond300.com/sites/default/files/R300_LowResDraft_200603.pdf (accessed on 2 September 2020).

43. City of Richmond RVAgreen 2050. What is RVAgreen 2050? Available online: https:/ / www.rvagreen2050.com/what-is-rvagreen2050 (accessed on 2 September 2020).

44. Engemann, K.; Bøcker, C.; Arge, L.; Tsirogiannis, C.; Mortensen, P.B.; Svennings, J. Residential green space in childhood is associated with lower risk of psychiatric disorders from adolescence into adulthood. Proc. Natl. Acad. Sci. USA 2019, 116, 5188-5193. [CrossRef]

45. The History of Scott's Addition. Available online: https://www.scottsaddition.com/history-of-scotts-addition/ (accessed on 25 November 2020).

46. About Scott's Addition. Available online: https://www.scottsaddition.com/about-scotts-addition/ (accessed on 25 November 2020).

47. Scott's Addition Demographics. Available online: https://www.point2homes.com/US/Neighborhood/VA/Scott-s-AdditionDemographics.html\#: \{\}:text=Scott \T1 \textquoterights\%20Addition\%20is\%20an \%20area, with\%20a\%20population\%20of $\% 20$ 6\%2C505.\&text=The\%20median\%20age \%20 of \%20the,married $\% 20$ and $\% 204 \% 2$ C133\%20being $\% 20$ single (accessed on 25 November 2020). 